\title{
$\mathrm{EMFG}$ 를 이용한 웹사이트의 동적 인터페이스 표현
}

\author{
김 은 숙 $^{\dagger}$ 여 정 모 $^{++}$ \\ 요 약
}

\begin{abstract}
웹사이트의 구조를 표현하고 설계하는 일반적인 방법으로 스토리보드나 사이트 맵 또는 플로우 차트 등을 사용하거나 또는 이들을 조합하여 사용하는 방법이 있다. 그러나 이들은 웹사이트의 전체 구조를 표현하기 어렵고 웹페이지 간의 세부적인 흐름 관계를 표현하기에 부적절한 면이 있다. 이러한 문제점을 다소 해결하기 위하여 EMFG(Extended Mark Flow Graph)를 이용하여 웹사이트를 표현하고 설계하려는 연구가 진행되 었다. 그런데 이러한 기존의 연구는 웹사이트의 정적인 부분들을 대부분 표현하였기 때문에 동적인 웹사이트의 인터페이스를 표현하고 설계하기 에는 부족한 점이 있다. 그리고 현재 인터넷의 생활화가 가속화되어 감에 따라 웹사이트의 구조가 더욱 다양하고 복잡하게 되었을 뿐 아니라 인 터페이스도 많은 부분에서 동적인 부분을 포함하게 되었다. 따라서 본 연구에서는 $\mathrm{EMFG}$ 를 사용하여 복잡하고 다양한 웹사이트의 구조뿐만 아 니라 동적인 인터페이스 - 예를 들어, 시간에 따라 변하는 페이지 구조 또는 마우스 동작에 따라 변하는 페이지 상태나 구조 등 - 를 표현하는 방법을 제시한다. 본 연구가 웹사이트를 설계하는데 많은 도움이 되고, 웹사이트의 유지보수에도 도움이 될 수 있을 것으로 기대한다.
\end{abstract}

키워드 : 확장된 마크흐름선도, 웹사이트의 구조, 동적 인터페이스, 웹사이트의 정적인 부분

\section{The Dynamic Interface Representation of Web Sites using EMFG}

\author{
Eun Sook $\mathrm{Kim}^{+}$. Jeong Mo Yeo ${ }^{++}$
}

\begin{abstract}
Web designers generally use a story board, a site map, a flow chart or the combination of these for representing web sites. But these methods are difficult to represent the entire architecture of a web site, and may be not adaptive for describing the detail flow of web pages. To solve these problems to some degree, there were works using EMFG(Extended Mark Flow Graph) recently. However the conventional EMFG representation method is not adaptive to represent the dynamic interface of web sites because that cover only the static parts of a web site. Internet utilization is rapidly growing in our life and we cannot imagine the worlds of work, study and business without internet. And web sites recently have not only more complex and various architecture but also web pages containing the dynamic interface. Therefore we propose the representation method of these web sites - for example, a web site containing varying pages with time and varying page status or contents with mouse operations - using EMFG. We expect our work to be help the design and maintenance of web sites.
\end{abstract}

Keywords: EMFG(Extended Mark Flow Graph), Architecture Of Web Sites, Dynamic Interface, Static Parts Of A Web Site

\section{1. 서}

인터넷 활성화와 사용자 정보화 수준이 높아지면서 웹사 이트의 환경 역시 크게 달라지고 있다[1]. 인터넷 사용자들 은 보다 많은 정보를 보다 빠르고 편리하게 제공받기를 요 구하고 있으며 이러한 요구에 맞추어 최근 대부분의 웹사이 트에서 네비게이션 구조는 다양한 형태의 동적 구조를 이루 고 있는 추세이다. 하지만 많은 웹사이트에서 나타나는 동 적 네비게이션 구조를 나타낼 수 있는 체계적인 표현 방법

\footnotetext{
† 준 회 원: 부경대학교 교육대학원 전산교육전공

†† 정 회 원: 부경대학교 전자컴퓨터정보통신공학부 교수 논문접수: 2008 년 5월 19일

수 정 일:1차 2008년 7월 14일, 2차 2008년 8월 18일

심사완료 : 2008년 8월 28일
}

이 제시되지 않아 이러한 웹사이트 구조의 정확한 표현이 어려우며 이에 따라 동적 웹사이트의 명확하고 체계적인 설 계가 힘들다는 문제점이 있다.

윕사이트의 효율적인 설계와 관리는 웹사이트의 개발과 유지보수에 있어 핵심적인 요소라 할 수 있다[2,3]. 일반적인 웹사이트 표현기법으로 스토리보드, 사이트 맵, 플로우 차트 등이 이용되고 있다[4-6]. 이러한 방법을 하나 혹은 둘 이상 함께 사용하여 웹사이트를 표현할 때, 웹사이트 내에서 일어 나는 사용자의 웹페이지 이동표현 및 웹사이트의 전체 구조 와 웹페이지간의 세부적인 흐름을 파악하기 어려우며 $[7,8]$ 웹사이트의 설계 및 관리가 힘들다는 문제점이 있다.

따라서 이를 보완하기 위한 방법으로 웹사이트의 표현에 페트리네트(PN: PetriNet)[9-11]에서 파생된 EMFG(Extended 
Mark Flow Graph)[12-19]를 이용하는 방법이 연구되고 있 다. 기존연구 $[7,8,20]$ 에서는 웹사이트의 정적인 부분들을 대 부분 표현하였으며 마우스 클릭 동작에 따른 웹페이지의 이 동관계 표현이 연구의 중점이었다. 그래서 기존연구[7,8,20] 에서는 웹사이트의 이미지나 텍스트, 메뉴 등의 네비게이션 을 정적인 구조로만 가정하고 이러한 정적 인터페이스에서 마우스 클릭 동작에 따른 웹페이지간 이동관계를 표현하였 으며 이러한 관계에서 나타나는 반복구조의 간략화를 제시 하였다. 최근 웹사이트의 환경은 이전과 많은 차이점이 있 으며 대표적인 것 중 하나가 동적 네비게이션 구조이다. 현 재 대부분의 웹사이트는 임의의 시간간격 후 또는 사용자의 마우스 동작에 따라 이미지나 텍스트 등 네비게이션이 바뀌 는 동적 구조이다. 하지만 기존연구 $[7,8,20]$ 에서 이러한 동 적 구조를 표현할 수 있는 방법이 제시되지 않아 웹사이트 의 동적 인터페이스 구조를 표현할 수 없다는 한계점이 있 다. 현재 대부분 웹사이트의 인터페이스 환경이 동적 구조 란 점을 감안할 때 이를 체계화 할 수 있는 표현방법에 대 한 연구가 필요하다.

따라서 본 연구에서는 $\mathrm{EMFG}$ 를 이용하여 웹사이트의 동 적 인터페이스를 표현할 수 있는 방법을 제시하여 웹사이트 의 구조를 보다 정확하고 체계적으로 설계할 수 있도록 도 움이 되고자 한다.

\section{2. 관련 연구}

\section{1 웹사이트의 EMFG 표현}

웹사이트의 구조를 EMFG로 표현할 때, 박스는 웹사이트 를 구성하는 웹페이지 상태나 네비게이션 상태 또는 하이퍼 링크 등의 선택동작을 표현하고 트랜지션은 웹페이지 간의 이동을 표현하며, 아크는 웹페이지 간의 이동 방향을 표현 한다. 그리고 박스의 마크는 박스에 해당하는 상태가 활성 화되어 있음을 의미한다[7, 8].

기존 연구 $[7,8,20]$ 에서 박스는 윕페이지 상태를 나타내는 페이지 상태박스 $(\mathrm{P})$, 게시판과 같이 하나의 프로그램 모듈처 럼 동작하는 상태박스 $(\mathrm{B})$, 사용자에 의한 정보 입력상태를 나타내는 정보 상태박스(I), 네비게이션바에 있는 메뉴의 선 택을 나타내는 네비게이션 하이퍼링크 상태박스 $(\mathrm{HN})$, 컨텐 츠 내의 문맥 네비게이션의 선택을 나타내는 문맥 네비게이 션 하이퍼링크 상태박스 $(\mathrm{HC})$ 로 분류하였다. 이와 같이 분류 하여 표현하였을 때 박스명으로 하이퍼링크 상태박스와 페 이지 상태박스의 구분은 쉽지만 해당 페이지를 찾아가는 하 이퍼링크 경로의 직관적인 파악이 어렵다는 문제점이 있다. 따라서 본 연구에서는 이를 개선하여 표기할 것이다.

2.2 웹사이트에서 이동관계 유형 및 반복구조의 EMFG 표현 기존 연구 $[7,8,20]$ 에서 웹페이지간 이동관계를 표현하였으 며 이러한 표현에서 나타나는 반복구조를 직렬반복구조와 병 렬반복구조로 구분하여 간략화 하였다. 직렬반복구조는 이중 박스를 사용하여 간략화 하였으며 병렬반복구조는 기호[ ]
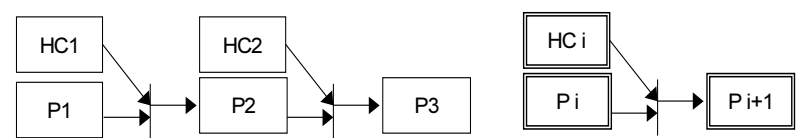

$(1 \leq \mathrm{i} \leq 2)$

(a) 유형1 (직렬반복구조와 간략화의 표현)
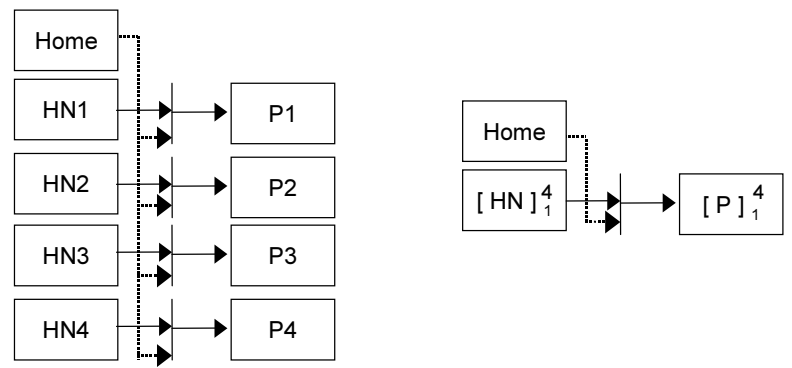

(b) 유형2 (병렬반복구조와 간략화의 표현)
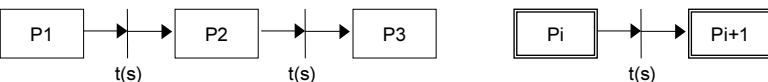

$(1 \leq \mathrm{i} \leq 2)$

(c) 유형3 (시간 $\mathrm{s}$ 에 의한 이동과 간략화의 표현)

(그림 1) 웹페이지 간 이동관계 유형과 반복구조의 EMFG 표현

를 사용하여 간략화 표현하였다. (그림 1)은 대표적인 형태 의 웹페이지 간 이동관계를 분류한 것이며 이들 각각의 반 복구조를 간략화하여 표현한 것이다.

(그림 1)(a)는 사용자가 원하는 최종 컨텐츠 페이지에 도 달하기 위해 문맥 네비게이션 $\mathrm{HCl}$ 을 선택하면 웹페이지 $\mathrm{P} 1$ 이 사라지고 다른 웹페이지 $\mathrm{P} 2$ 가 나타나며 다시 문맥 네비 게이션 $\mathrm{HC} 2$ 를 선택하면 웹페이지 $\mathrm{P} 3$ 이 나타나는 직렬반복 구조이다. (그림 1)(a)의 오른쪽 그림은 이러한 직렬반복구 조를 이중 박스로 간략화 표현한 것이다. (그림 1)(b)는 윕 페이지 Home에서 전역 - 지역 네비게이션 메뉴 HN1부터 $\mathrm{HN} 4$ 까지 선택하면 각각의 메뉴에 해당하는 웹페이지 P1부 터 $\mathrm{P} 4$ 까지 이동하는 동일한 유형의 페이지 이동을 나타낸 것이다. (그림 1 )(b)의 오른쪽 그림은 이러한 병렬반복구조 를 기호 []$_{m}^{n}$ 를 사용하여 간략화한 것이다. (그림 1 )(c)는 어 떤 웹페이지 P1에서 일정한 시간이 지나면 다른 웹페이지 $\mathrm{P} 2$ 로 이동하고 다시 일정한 시간이 지나면 웹페이지 $\mathrm{P} 3$ 으 로 이동하는 직렬반복구조의 표현 및 간략화 표현이다.

\section{3. 웹사이트에서 동적 인터페이스의 EMFG 표현}

\section{1 박스명 표기의 개선}

본 연구에서는 기존 연구[20]의 박스명 중 네비게이션 하 이퍼링크 상태박스 $(\mathrm{HN})$, 문맥 네비게이션 하이퍼링크 상태 박스 $(\mathrm{HC})$, 정보입력 상태박스(I)는 동일하게 적용하였고 그 외 박스명은 개선 및 추가하여 적용하였다. <표 $1>$ 은 본 연 구에서 개선 및 추가된 박스명 규칙을 정리한 표이다. 
〈표 1〉박스명 규칙

\begin{tabular}{|c|c|}
\hline 박스명 & 의미 \\
\hline \hline $\mathrm{HD}$ & 동적 네비게이션 하이퍼링크 상태박스 \\
\hline $\mathrm{HA}$ & 보조 네비게이션 하이퍼링크 상태박스 \\
\hline $\mathrm{HB}$ & Board 관련 네비게이션 하이퍼링크 상태박스 \\
\hline Refresh & Refresh 상태를 나타내는 상태박스 \\
\hline $\mathrm{P}$ 접두어 & 웹페이지 상태를 나타내는 페이지 상태박스 \\
\hline $\mathrm{B}$ 접두어 & 게시판처럼 하나의 프로그램 모듈처럼 동작하는 상태박스 \\
\hline C 접두어 & Mouse Click 동작을 나타내는 상태박스 \\
\hline $\mathrm{O}$ 접두어 & Mouse Over/Out 동작을 나타내는 상태박스 \\
\hline
\end{tabular}

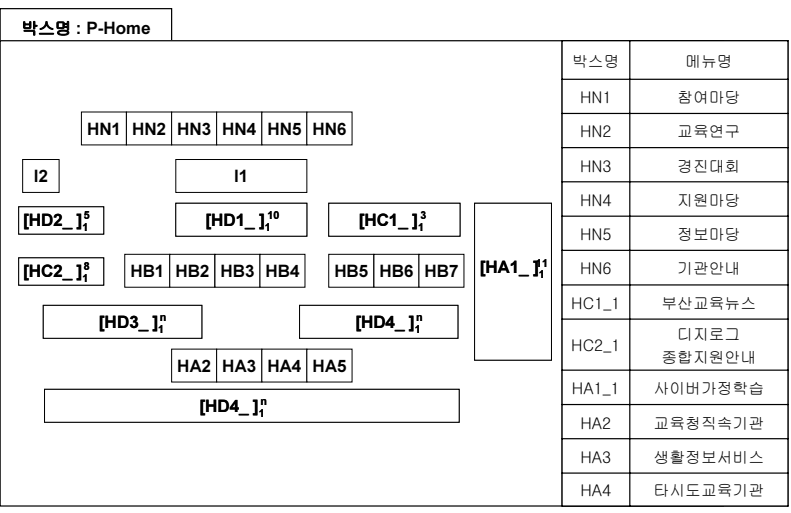

(그림 2) 부산에듀넷의 웹페이지 구성도 예

또한 박스명 뒤에 숫자를 덧붙여 박스명만으로 해당 페이 지를 찾아가는 하이퍼링크 경로를 직관적으로 파악할 수 있 게 하였다.

\section{2 웹페이지 구성도}

‘웹페이지 구성도’란 메인 웹페이지의 메뉴를 하이퍼링크 상태 박스로 표현하여 배치하고 우측에는 하이퍼링크 상태 박스명과 그것에 대응되는 메뉴명을 표 형태로 나타낸 배치 도를 의미한다. 예를 들어, (그림 2)는 부산에듀넷 사이트의 웹페이지 구성도를 나타낸 것이다.

(그림 2)에서 부산 에듀넷의 메인 페이지를 박스명 P-Home 으로 하였으며 메인 페이지에 있는 메뉴를 박스명 규칙에 따라 하이퍼링크 상태 박스로 나타내고 해당 위치에 배치하 였다. 그리고 박스명에 해당하는 메뉴명을 표로 나타내어 사용자가 '웹페이지 구성도'를 쉽게 파악할 수 있게 하였다.

\section{3 하이퍼링크 상태박스표}

‘하이퍼링크 상태박스표'란 웹사이트에 들어가는 모든 메 뉴를 기준으로 메뉴명, 하이퍼링크 상태 박스명, 페이지 상태 박스명을 표 형태로 나타낸 것을 말한다. 예를 들어 <표 2> 는 부산에듀넷 사이트의 하이퍼링크 상태박스표의 일부를 나 타낸 것이다.

<표 2>에서 페이지 상태 박스명은 그 페이지에 접근할 수 있는 하이퍼링크 상태 박스명 앞에 $\mathrm{P}$ 접두어를 붙여 페이 지 박스명으로 사용하였다.

웹사이트 설계자 입장에서는 하이퍼링크 상태 박스명을
〈표 2〉부산에듀넷의 하이퍼링크 상태박스표 예

\begin{tabular}{|c|c|c|}
\hline 메뉴명 & 하이퍼링크 상태 박스명 & 페이지 상태 박스명 \\
\hline \hline 인사말 & HN6_1 & P-HN6_1 \\
\hline 설립목적 & HN6_2 & P-HN6_2 \\
\hline 조직현황 & HN6_3 & P-HN6_3 \\
\hline
\end{tabular}

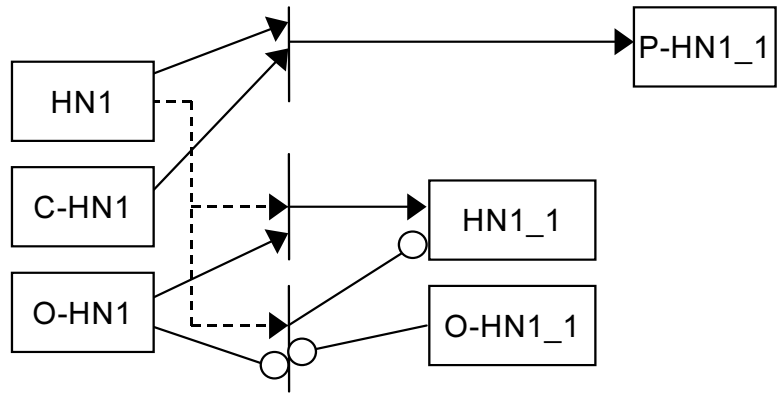

(그림 3) 하이퍼링크 상태박스에서 Mouse Click/Over/Out 동작의 표현

메뉴 파일명으로 사용하고, 페이지 박스명을 웹페이지 파일 명으로 적용하여 사용함으로써 복잡한 웹사이트의 수많은 파일들을 체계적으로 구성하고 관리할 수 있다. 이처럼 '웹 페이지 구성도'와 '하이퍼링크 상태박스표'를 통해 설계자는 사이트를 보다 효율적으로 설계 및 관리할 수 있고 사용자 는 $\mathrm{EMFG}$ 를 이용한 웹사이트의 표현을 보다 쉽게 이해할 수 있다.

\section{4 네비게이션 하이퍼링크 상태박스에서 Mouse 동작의 EMFG 표현}

최근 많은 웹사이트에서 사용자의 마우스 동작에 따라 서 브메뉴가 보이거나 사라지는가 하면 동영상이 재생이 되거 나 멈추기도 한다. 그리고 뉴스 관련 텍스트나 이미지, 배너 등도 계속해서 동적으로 바뀌거나 사용자의 마우스 동작에 따라 움직임을 멈추거나 다시 동적으로 바뀌는 등 다양한 구조를 이루고 있다.

본 연구에서는 이러한 웹사이트의 동적인 구조를 표현하기 위해 하이퍼링크 상태박스에서 Mouse Click 동작과 Mouse Over/Out 동작을 구분하여 나타내었다.

[정리 1] 하이퍼링크 상태박스의 Mouse Click/Over/Out 동작은 (그림 3)과 같이 표현할 수 있다. 여기서 박스명의 표기는 <표 1>과 <표 2>를 따랐으며, 첫 페이지를 나타내 는 페이지 상태박스(P-Home)는 생략하여 표현할 수 있다.

증명) (그림 3)에서 웹사이트의 첫 페이지인 $\mathrm{P}-\mathrm{Home}$ 에 서 HN1메뉴를 Mouse Click(박스 C-HN1) 함에 따라 일반 아크의 점화조건이 만족되어 P-HN1_1 페이지로 이동하게 됨을 의미하므로 타당하다.

그리고 $\mathrm{HN} 1$ 메뉴에 Mouse Over(박스 O-HN1) 동작 시 일반아크의 점화조건이 만족되어 HN1의 서브메뉴인 HN1_1 이 보여짐을 의미하므로 타당하다. 또한 $\mathrm{HN} 1$ 메뉴와 서브메 뉴 HN1_1에서 Mouse Out(박스 O-HN1, O-HN1_1) 동작 
시 역아크의 점화조건이 만족되어 서브메뉴 HN1_1이 사라 지게 됨을 의미하므로 타당하다.

대부분의 웹사이트에서 사용자가 전역 네비게이션 메뉴에 Mouse Over/Out 동작 시 (그림 3)과 같이 동작하는 반면, 최 근에는 웹사이트의 특징에 적합하게 하위메뉴를 보여주는 방 식도 다양하다. 한 예로 사용자가 상위 메뉴에 Mouse Over 후 Mouse Out 동작 시 Mouse Over의 상태를 그대로 유지 하게 하여 편리성을 더해주는 구조도 많이 나타나고 있다.

부산 에듀넷의 경우, 전역 네비게이션바에 있는 상위 메 뉴를 클릭하여 해당 페이지에 들어간 상태에서는 Mouse Out 동작 시에도 해당 서브 메뉴가 보이는 상태를 유지하고 있는 것을 볼 수 있다. 이와 같은 구조는 (그림 3)을 변형시 켜 적용할 수 있다.

[정리 2] 하이퍼링크 상태박스에서 Mouse Out 동작 시 서브메뉴가 보이는 상태를 유지하는 구조는 (그림 4)와 같 이 표현할 수 있다. 여기서 박스명의 표기는 <표 $1>$ 과 <표 $2>$ 를 따랐으며, 첫 페이지를 나타내는 페이지 상태박스 (P-Home)는 생략하여 표현할 수 있다.

증명) (그림 4)는 사용자가 HN1에서 Mouse Over(박스 O-HN1) 할 경우 일반아크의 점화조건이 만족되어 서브메뉴 $\mathrm{HN} 1$ 1이 나타나며 Mouse Out(박스 O-HN1) 한 경우 역아 크의 점화조건이 만족되어 서브메뉴가 나타난 상태를 유지함 을 의미하므로 타당하다.

\subsection{Mouse 동작에 따른 EMFG 표현의 간략화}

하이퍼링크 상태박스에서 사용자의 Mouse 동작에 따른 웹페이지의 흐름을 $\mathrm{EMFG}$ 로 표현하였을 때, 박스의 수가 많아지고 다소 복잡해지는 단점이 있다. 따라서 본 연구에 서는 Mouse 동작에 따른 $\mathrm{EMFG}$ 를 간략하게 표현할 수 있 는 방법을 제시하였다.

[정의 1] 하이퍼링크 상태박스에서 Mouse Click 동작을 나타내는 상태박스는 하이퍼링크 상태박스 상단을 이중선으 로 표현하고, Mouse Click 동작을 나타내는 일반아크는 박 스 상단에서 시작하도록 표현한다.

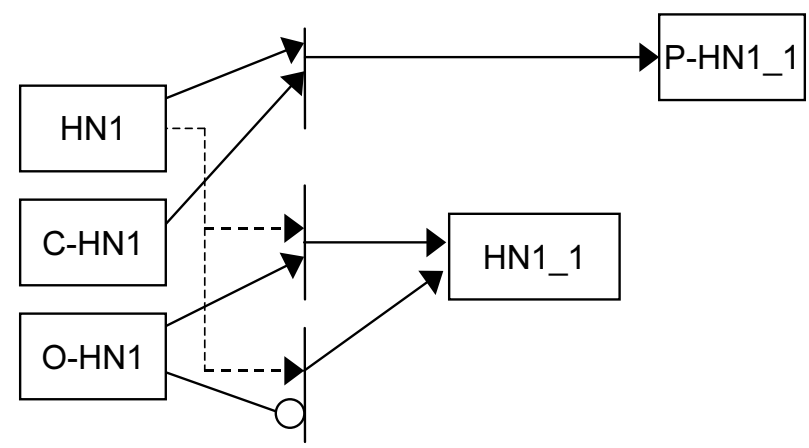

(그림 4) Mouse Out 동작 시 서브메뉴가 보이는 상태 유지의 표현
[정의 2] 하이퍼링크 상태박스에서 Mouse Over 동작을 나타내는 상태박스는 하이퍼링크 상태박스 하단을 이중선으 로 표현하고, Mouse Over 동작을 나타내는 일반아크는 박 스 하단에서 시작하도록 표현한다.

[정의 3] 하이퍼링크 상태박스에서 Mouse Out 동작을 나 타내는 상태박스는 하이퍼링크 상태박스 하단을 이중선으로 표현하고, Mouse Out 동작을 나타내는 역아크는 박스 중간 에서 시작하도록 표현한다.

[정리 3] 하이퍼링크 상태박스에서 Mouse Click/Over/Out 동작을 나타내는 상태박스는 하이퍼링크 상태박스의 상단/ 하단/하단을 이중선으로 표현할 수 있고, Mouse Click/Over 동작을 나타내는 일반아크는 박스의 상단/하단에서 시작하 도록 표현할 수 있으며 Mouse Out 동작을 나타내는 역아크 는 박스의 중간에서 시작하도록 표현할 수 있다.

증명) [정의 1]과 [정의 2] 및 [정의 3]에 의해 자명하다.

(그림 5)는 [정의 1], [정의 2], [정의 3], [정리 3] 에 의해 Mouse Click/Over/Out 동작을 표현한 것이다.

예를 들어, (그림 6)은 (그림 3)을 간략화 표현한 것이다. [정리 3]에 따라 하이퍼링크 상태박스 HN1은 Mouse Click 과 Mouse Over/Out 동작을 포함한 상태박스이다. Mouse Click 동작 시 상단의 일반아크가 점화되어 웹페이지 P-HN1_1로 이동하고 Mouse Over 동작 시 하단의 일반아크가 점화되어 서브메뉴 HN1_1이 나타나며 상위메뉴와 서브메뉴에 Mouse Out 동작 시 역아크의 점화조건이 만족되어 서브메뉴 HN1_1 이 사라진다.

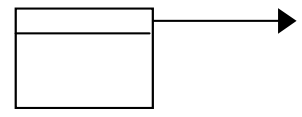

(a)Mouse Click

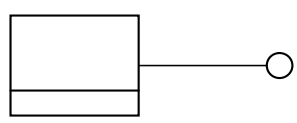

(c)Mouse Out
(b)Mouse Over

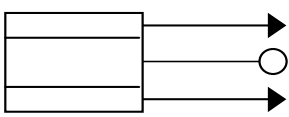

(d)Mouse Click/Over/Out

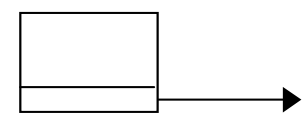

(그림 5) Mouse Click/Over/Out 동작의 간략화 표현

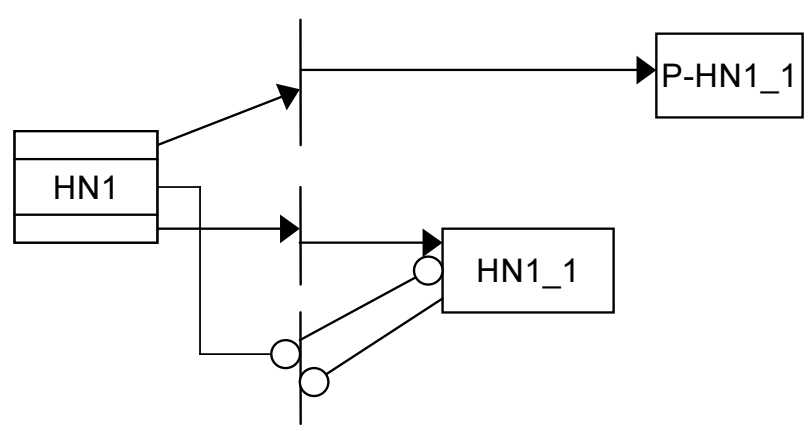

(그림 6) (그림 3)의 간략화 표현 
3.6 동적 하이퍼링크 상태박스의 EMFG 표현 및 간략화

요즘 많은 사이트에서 뉴스, 이미지, 배너, 텍스트 등이 고정되어 있지 않고 임의의 시간 간격 후 또는 Refresh에 의해 계속해서 변하는 것을 볼 수 있다. 이러한 구조는 쇼 핑몰 사이트에서 상품의 이미지를 방문자에게 보여준다거나 포털 사이트에서 실시간 뉴스를 방문자에게 보여줄 때 더욱 많이 쓰이고 있다. 이처럼 본 연구에서 사용자의 마우스 동 작과 상관없이 시간 간격에 의해 동적으로 바뀌는 이미지, 텍스트 등의 동작을 표현하는 방법을 제시하였다.

[정리 4] 임의의 시간 간격 후 또는 Refresh에 의해 계속 해서 바뀌는 이미지나 배너 등의 동적 하이퍼링크 상태박스 의 동작은 (그림 7)과 같이 표현할 수 있다.

증명) (그림 7)(a)에서 동적 하이퍼링크 상태박스 HD1은 임의의 시간 $\mathrm{t}(\mathrm{s})$ 에 의해 $\mathrm{HD} 2$ 로 바뀌거나 또는 Refresh(새 로고침)에 의해 다음 하이퍼링크 상태박스로 바뀔 수 있음 을 의미한다. 또한 이와 같은 변화는 다시 처음 상태박스 $\mathrm{HD} 1$ 으로 돌아가 계속해서 반복하게 됨을 의미하므로 타당 하다. 그리고 (그림 7)(a)는 직렬반복구조이므로 이중박스를 사용하여 (그림 7)(b)와 같이 간략화 표현된 것은 타당하다.

(그림 7)에서 $\mathrm{t}(\mathrm{s})$ 는 임의의 시간간격을 나타내는 단위시 간이다. 단위시간은 동작의 속도에 따라 $\mathrm{s}$ 대신 숫자로 표현 가능하며 큰 숫자는 긴 시간을 나타내며 작은 숫자는 짧은 시간을 나타낸다.

또한 Refresh와 상관없이 임의의 시간간격에 의해서만 계 속해서 변하는 동적 하이퍼링크 상태박스의 경우, Refresh 상태박스를 제거한 형태로 적용하여 표현할 수 있다.

\section{7. 동적 인터페이스 반복구조의 EMFG 표현}

하이퍼링크 상태박스에서 사용자의 Mouse 동작에 따른 웹페이지의 흐름을 $\mathrm{EMFG}$ 로 표현하였을 때, 동일한 유형이 반복되어 나타나는 경우가 많다. 동적 인터페이스에서 나타
나는 반복구조는 직렬반복구조와 병렬반복구조로 분류되며 기존 연구에서 제시된 간략화 방법과 본 연구에서 제시된 간략화 방법을 통합하여 표현할 수 있는 방법을 제시한다.

[정리 5] Mouse Click/Over/Out 동작을 나타내는 하이퍼 링크 상태박스의 직렬반복구조는 Mouse Click/Over/Out 동 작의 간략화 된 상태박스와 이중박스를 함께 사용할 수 있다.

증명) 하이퍼링크 상태박스의 이동관계를 $\mathrm{EMFG}$ 로 표현하 면 직렬반복구조와 병렬반복구조로 분류되며 직렬반복구조는 기존 연구[11]의 [정의 2]에 따라 이중박스로 간략화 표현된 다. 그리고 하이퍼링크 상태박스에서 Mouse Click/Over/Out 동작의 상태박스는 [정의 1], [정의 2], [정의 3], [정리 3]에 의해 간략화 된다. 따라서 하이퍼링크 상태박스의 직렬반복 구조는 Mouse Click/Over/Out 동작의 상태박스와 이중박스 를 함께 사용할 수 있으므로 타당하다.

[정리 6] Mouse Click/Over/Out 동작을 나타내는 하이퍼 링크 상태박스의 병렬반복구조는 Mouse Click/Over/Out 동 작의 간략화 된 상태박스와 기호 [ ] $]_{\mathrm{m}}^{\mathrm{n}}$ 를 함께 사용할 수 있다.

증명) 하이퍼링크 상태박스의 이동관계를 $\mathrm{EMFG}$ 로 표현하 면 직렬반복구조와 병렬반복구조로 분류되며 병렬반복구조는 기존 연구[11]의 [정의 4]에 따라 기호 [ ] $\mathrm{m}_{\mathrm{m}}^{\mathrm{n}}$ 간략화 표현된 다. 그리고 하이퍼링크 상태박스에서 Mouse Click/Over/Out 동작의 상태박스는 [정의 1], [정의 2], [정의 3], [정리 3]에 의해 간략화 된다. 따라서 하이퍼링크 상태박스의 병렬반복 구조는 Mouse Click/Over/Out 동작의 상태박스와 기호 [ ] $]_{m}^{\mathrm{n}}$ 를 함께 사용할 수 있으므로 타당하다.

\section{4. 적용 예}

부산광역시 교육정보연구원(부산에듀넷 http://www.busanedu. net) 사이트에서 네비게이션 하이퍼링크 상태박스 $\mathrm{HN} 2$, 동적 하이퍼링크 상태박스 $\mathrm{HD} 1$ 의 동작을 적용하여 표현하였다.

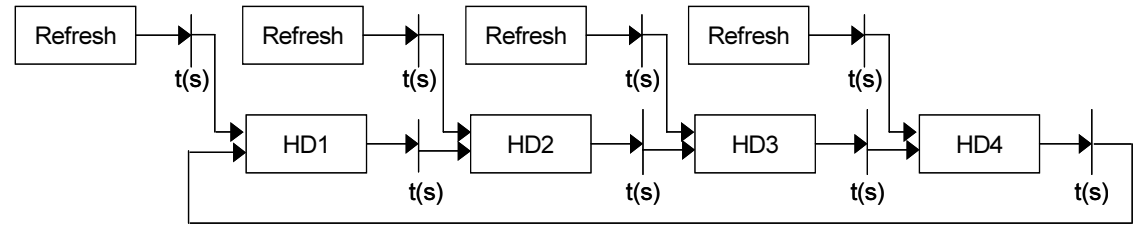

(a) 간략화 전

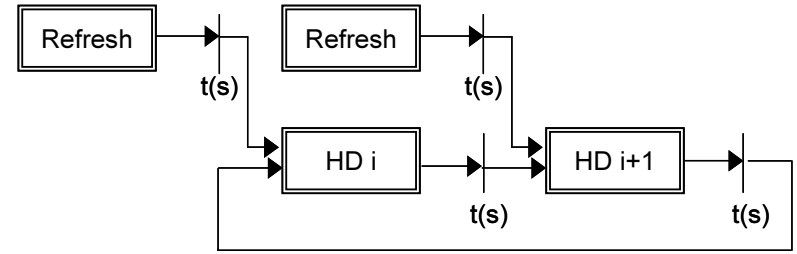

$(1 \leq \mathrm{i} \leq 3)$

(b) 간략화 후

(그림 7) 임의의 시간 또는 Refresh에 의해 바뀌는 동적 하이퍼링크 상태박스의 표현 


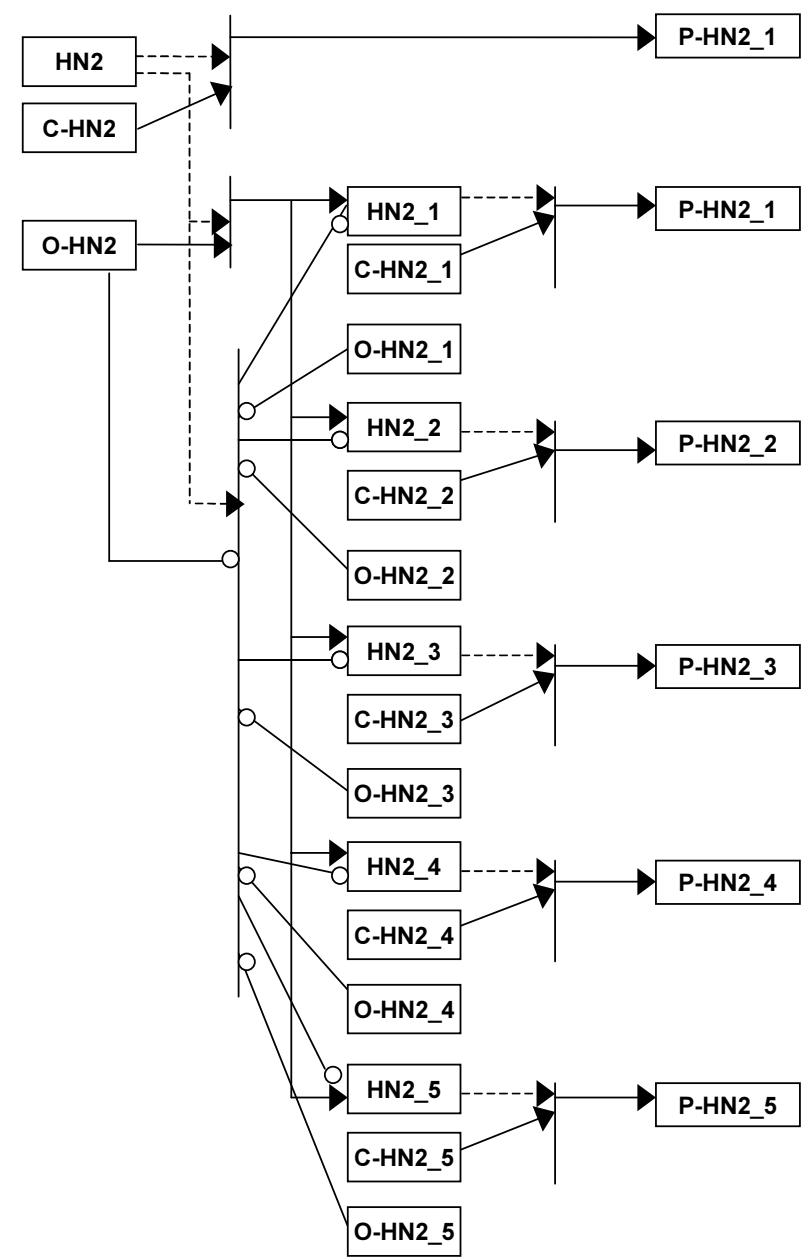

(a) 간략화 전

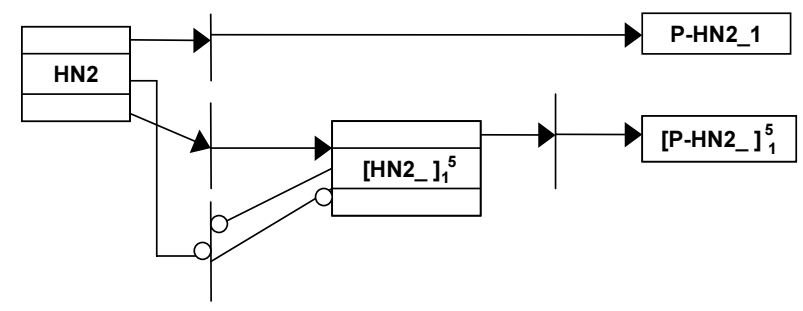

(b) 간략화 후

(그림 8) 부산에듀넷의 하이퍼링크 상태박스(HN2)의 동작 표현

4.1 전역 네비게이션 하이퍼링크 상태박스에서 Mouse 동작 의 EMFG 표현 예

부산에듀넷(http://www.busanedu.net) 사이트에서 교육연 구 메뉴(HN2) 하이퍼링크 상태박스의 마우스 동작에 따른 흐름을 표현하면 (그림 8)과 같으며 교육연구 메뉴(HN2)의 서브 메뉴 동작은 부산에듀넷의 첫 페이지에서 동작을 기준 으로 표현한 것이다.

부산에듀넷 사이트의 첫 페이지에서 사용자가 교육연구 메 뉴(HN2)에 Mouse Over 하면 서브 메뉴 5개가 보여지며 각 각의 서브 메뉴를 클릭하였을 때 해당 페이지로 이동하게 된 다. 그리고 상위메뉴 $\mathrm{HN} 2$ 와 $\mathrm{HN} 2$ 의 서브 메뉴로부터 Mouse

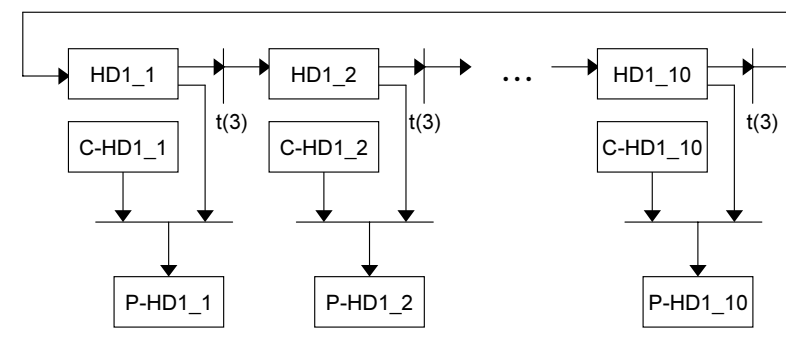

(a) 간략화 전

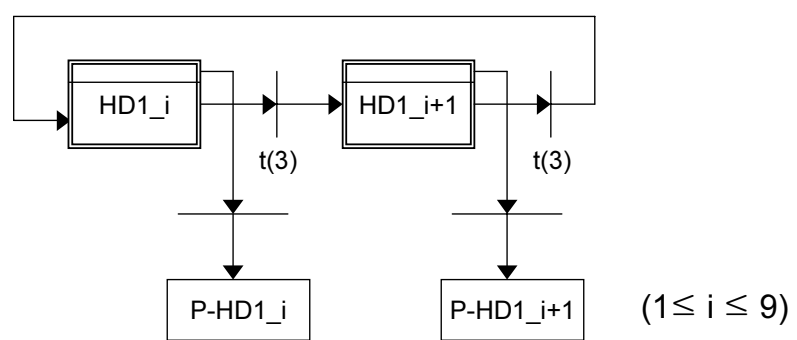

(b) 간략화 후

(그림 9) 부산에듀넷의 동적 하이퍼링크 상태박스(HD1)의 동 작 표현

Out 하게 되면 서브 메뉴가 사라진다. (그림 8)(a)에서 각각의 서브메뉴가 병렬반복구조임을 알 수 있다. (그림 8)(b)는 [정 리 6]에 의해 간략화 표현한 것이다. 이와 같이 간략화하면 적 은 수의 박스와 아크로써 전역 네비게이션 메뉴의 Mouse Click 동작에 따른 웹페이지 이동은 물론 Mouse Over/Out 동작에 따른 서브 메뉴의 변화까지도 파악할 수 있으므로 명확하고 효율적이다.

\section{2 동적 하이퍼링크 상태박스의 EMFG 표현 예}

최근 한 사이트에 표현하는 컨텐츠 양이 방대해짐으로서 많은 양을 하나의 사이트에 표현하기 어려움에 따라 사이트 의 첫 페이지에서 해당 메뉴를 클릭하게 되면 또 다른 하나 의 하위 사이트가 나타나는 구조로서 설계된 웹사이트가 많 다. 부산에듀넷도 첫 페이지에서 동적으로 움직이는 메뉴를 클릭하게 되면 그 메뉴에 해당하는 하위 웹사이트가 나타나 는 구조를 가지고 있다.

(그림 9)는 부산에듀넷의 동적 하이퍼링크 상태박스(HD1) 의 동작을 표현한 것이다. $\mathrm{HD} 1$ 은 하위 윕사이트로 가기 위 한 메뉴이며 일정한 시간이 지나면 다음 메뉴로 이동하는 동적인 구조로 되어있다. (그림 9)(a)는 직렬반복구조임을 알 수 있으며 (그림 9)(b)는 [정리 5]에 의해 간략화 표현한 것이다.

본 연구에서는 기존 연구에서 동적 네비게이션 구조를 표 현할 수 없다는 한계점을 극복하고 보완하고자 웹페이지의 동적 흐름 및 사용자의 마우스 동작에 따른 웹페이지의 흐름 을 $\mathrm{EMFG}$ 로 나타내고 이것의 간략화 표현을 제시하였다. 그 결과, 기존연구에서 불가능했던 동적 인터페이스 구조의 표현 이 가능하며 마우스 동작에 따른 $\mathrm{EMFG}$ 표현을 간략화 함으 로써 하나의 하이퍼링크 상태박스로 Mouse Click/Over/Out 의 모든 상태 표현이 가능하므로 효율적이다. 또한 동적 네비 
게이션의 반복구조를 간략화 함으로써 $\mathrm{EMFG}$ 를 이용한 동적 인터페이스의 표현이 체계적이고 효율적이며 명확하다.

\section{5. 결 론}

웹사이트를 보다 명확하게 표현하고 효율적으로 설계하기 위해 직관적이고 개념적인 설계가 가능한 $\mathrm{EMFG}$ 를 이용할 수 있다. 인터넷의 생활화가 가속화 되어감에 따라 웹사이 트는 사용자에게 보다 편리한 동적 네비게이션 구조로써 정 보를 제공하려는 경향이 짙어지고 있다. 그러나 동적 네비 게이션 구조를 나타낼 수 있는 체계적인 방법이 없어 이러 한 웹사이트 구조를 표현할 수 있는 방법에 대한 연구가 필 요하다.

본 연구에서는 스토리보드, 사이트맵, 플로우차트 등 웹사 이트의 일반적인 표현기법과 기존연구에서 제시된 표현방법 으로 동적 인터페이스의 구조를 표현할 수 없다는 한계점을 보완하고자 웹페이지의 동적 흐름 및 사용자의 마우스 동작 에 따른 웹페이지의 흐름을 $\mathrm{EMFG}$ 로 나타내고 이것의 간략 화 표현을 제시하였다. 사용자의 마우스 동작에 따른 웹페 이지의 흐름을 일반아크와 역아크로 표현하고 네비게이션의 Mouse Click/Over/Out 동작을 나타내는 상태박스는 박스의 상단과 하단을 이중선으로 표현하고 각각의 위치에서 아크가 시작되도록 간략화 하였다. 또한 사용자의 마우스 동작과 상 관없이 Refresh나 시간간격에 의해 계속 변하는 동적 네비게 이션 구조의 표현 방법을 제안하였으며 기존 연구를 개선하 여 동적 인터페이스 반복구조의 간략화 표현방법을 제시하였 다. 그 결과, 기존연구에서 불가능했던 동적 인터페이스 구조 의 표현이 가능하며 마우스 동작에 따른 $\mathrm{EMFG}$ 표현을 간략 화 함으로써 하나의 하이퍼링크 상태박스로 Mouse Click/ Over/Out의 모든 상태 표현이 가능하므로 효율적이다. 또한 동적 네비게이션의 반복구조를 간략화 함으로써 $\mathrm{EMFG}$ 를 이용한 동적 인터페이스의 표현이 체계적이고 효율적이다.

본 연구에서는 동적 인터페이스의 구조의 표현방법을 제 시하고 $\mathrm{EMFG}$ 를 간략화 함으로써 웹사이트의 구조를 보다 효율적으로 파악할 수 있고 체계적인 웹사이트의 설계에 도 움이 되고자 한다. 향후, 기존에 설계된 $\mathrm{EMFG}$ 를 이용한 웹 사이트 표현방법의 개선점을 찾아내어 더욱 다양한 형태로 발전하게 될 웹사이트의 구조에 적합한 $\mathrm{EMFG}$ 설계 기법에 관한 연구가 필요할 것이다.

\section{참 고 문 헌}

[1] 박재희, 유대승, "웹 사이트의 효율적인 구조 관리와 평가," 한국컴퓨터종합학술대회 2005 논문집, Vol.32, No.1(B), pp. 409-411, 2005.

[2] Benoit Leger, Jean-Christophe Cimetiere, "Web Load and Performance Testing Tools," "www.trendmarkers.com," 2000.

[3] Hung Q. Nguyen, "Testing Applications on the Web,"
Wiley Computer Publishing, 2001

[4] Louis Rosenfeld, Peter Morville, "Information Architecture for the World Wide Web," O’REILLY, 2006.

[5] Jennifer Fleming, "WEB Navigation; Designing the User Experience," O’REILLY, 1998.

[6] 한동환, 웹 기획, 정보게이트, pp. 272-303, 2002.

[7] 정안나, “쇼핑몰 사이트의 $\mathrm{EMFG}$ 표현에 관한 연구," 부경 대학교 교육대학원 석사학위논문, August, 2003.

[8] 정은옥, " $\mathrm{EMFG}$ 를 이용한 쇼핑몰 사이트의 정보구조 및 링 크구조 표현," 부경대학교 교육대학원 석사학위논문, August, 2004.

[9] Tomohiro Murata, Norihisa Komoda, Kunikai Matsumoto and Koichi Haruna, "A Petri Net-Based Controller for Flexible and Maintainable Sequence Control and its Applications in Factory Automation," IEEE Trans. Industrial Electronics, Vol.IE-22, No.1, 1986.

[10] T. Murata, "Petri nets: Properties, Analysis and Applications," Proc. IEEE, Vol.77, No.4, pp.541-580, 1989.

[11] Rene David and Hassane Alla, "Petri Nets for Modeling of Dynamic Systems a Survey," Auomatica, Vol.30, No.2, pp.175-202, 1994

[12] 여정모, "이산제어시스템 설계를 위한 확장된 마크흐름선도 와 동작해석,” 정보처리논문지, Vol.5, No.7, pp.1986-1907, July, 1998.

[13] 여정모, "이산 시스템의 설계와 해석을 위한 확장된 마크흐 름선도의 재정의와 회로변환, 멀티미디어학회 논문지, Vol.1, No.2, pp.224-238, 1998. 12.

[14] 여정모, “확장된 마크흐름선도의 성질 및 간소화 알고리즘," 부경대학교 논문집 Vol.5, pp.17-28, December, 1998.

[15] 백형구, 김희정, 여정모, "릴레이 회로의 $\mathrm{EMFG}$ 표현에 관 한 연구," 부경대학교 논문집 Vol.6, pp.335-345, December, 2001.

[16] 백형구, 허후숙, 정명희, 여정모, “조건 아크를 이용한 릴레 이 회로의 EMFG 변환, 멀티미디어공학회, 2001년 추계학 술발표논문집, p.821-826, November, 2001.

[17] 김희정, 여정모, 서경룡, "EMFG의 개선된 동작해석 알고리 즘,” 정보처리학회논문지A,제9-A권 제3호, pp.371-378, September, 2002.

[18] 정명희, 김정수, 이태훈, 여정모, "추이적 행렬을 이용한 $\mathrm{EMFG}$ 의 마크흐름 분석,” 한국정보처리학회, 2003년 추계학술발 표논문집, pp.807-810, May, 2003.

[19] 허후숙, 여정모, “워크플로우의 EMFG 모델링과 분석," 정보 처리학회논문지D, 제10-D권 제7호, pp.1189-1196, December, 2003

[20] 여정모, 안정숙, "EMFG를 이용한 웹사이트 표현의 간략화," 정보처리학회논문지D, 제 $12-\mathrm{D}$ 권 제2호, pp.327-334, April, 2005 


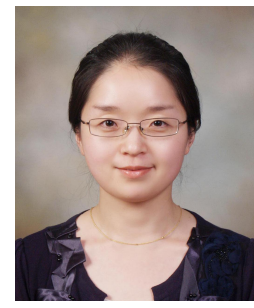

\section{김 은 숙}

e-mail :red71004@naver.com

1999년 동서대학교 환경공학과(학사)

2006년 한국방송통신대학교 컴퓨터과학과 (학사)

2008년 부경대학교 교육대학원 전산교육전공 (교육학석사)

관심분야: 전자상거래, 데이터베이스

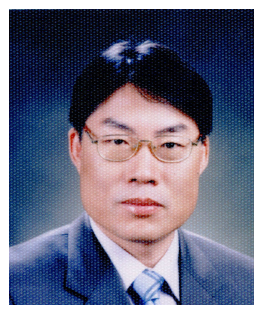

여 정 모

e-mail : yeo@pknu.ac.kr

1980년 동아대학교 전자공학과(학사)

1982년 부산대학교 대학원 전자공학과 (공학석사)

1993년 울산대학교 대학원 전자 및 전산기공학과(공학박사)

1986년 현 재 부경대학교 전자컴퓨터정보통신공학부 교수 관심분야: 전자상거래, 데이터베이스 